\title{
Methyl Jasmonate, a Degreening Alternative for Mandarin (Citrus Reticulata L.) Var. Arrayana Fruits
}

\author{
Carlos Alberto Gómez*, Aníbal Orlando Herrera**, Víctor Julio Flórez***, \\ Helber Balaguera-López**** \\ ** Chemist, MSc. Crop Physiology, PhD student, National University of Colombia - Faculty of Agricultural \\ Sciences. Bogotá Colombia. \\ **I.A. PhD. Associate professor. National University of Colombia - Faculty of Agricultural Sciences. Bogotá, \\ Colombia, \\ ***I.A. PhD. Associate professor. National University of Colombia - Faculty of Agricultural Sciences. Bogotá, \\ Colombia, \\ ****I.A. PhD. Professor of Pedagogical and Technological University of Colombia (UPTC), Tunja (Colombia) \\ and Faculty of Sciences, Biology Program, El Bosque University, Bogota (Colombia). \\ Corresponding Author: Carlos Alberto Gómez \\ Email id : dir.agronomicafaca@ucundinamarca.edu.co
}

\begin{abstract}
Mandarin accounts for a significant part of the Colombian citrus fruit production, the postharvest degreening of these products to attain pigmentation being a common practice when they are harvested in the tropics. The endogenous signaling molecules such as methyl jasmonate and ethylene are produced during fruit formation, and they play a key role in postharvest and stress responses. The latter is commonly used to degreen mandarin, which, however, exhibits low sensitivity to this compound. It is therefore important to establish degreening alternatives to ethylene. Thus, the aim of this study was to determine the effect of methyl jasmonate on the degreening of Arrayana mandarin (Citrus reticulata L.). For such purpose, respiration rate, weight loss, color index, total chlorophyll, total soluble solids, firmness and total acidity were determined. The treatments applied were: methyl jasmonate (MeJA) $1 \mu \mathrm{M} 24 \mathrm{~h}$, Ethylene (ET) $1000 \mathrm{ppm} 20 \mathrm{~min}, 1$-methylcyclopropene (1-MCP) $0.5 \mu \mathrm{L} \mathrm{L}^{-1} 2 \mathrm{~h}$; and the combinations 1-MCP + MeJA, 1- MCP + ET. Generally obtained with the MeJA and 1-MCP + MeJA treatments, the most significant results took place at 14 days after treatment implementation (DATI) for total titratable acidity, and at 4 DATI for total chlorophyll and color index. The TSS/acid ratio (maturity ratio) became constant since 7 DATI under the MeJA treatment. Thus, the use of MeJA after 1-MCP pretreatment comes to be an interesting degreening option, all the more when considering that these physiological responses have not been reported in previous studies.
\end{abstract}

Keywords: degreening, mandarin, methyl jasmonate, ethylene, 1-Methylcyclopropene

\section{INTRODUCTION}

The Colombian citrus sector has a significant economic importance. The effective area planted with these crops covers 38,317 ha, which produce $651,091 \mathrm{t}$ of fruit every year. Accounting for approximately $24 \%$ of the direct employments generated in the Colombian fruit sector, in 2013 mandarin yielded $127,450 \mathrm{t}$ in an area of 8,844 ha (14.4 t/ha). These figures correspond to $37.7 \%$ of the national citrus sector production, out of which $43.4 \%$ goes to the local market [18].

However, the offer of this product at the national level does not satisfy the demand. In addition, product quality is rather poor, mainly due to inadequate postharvest management conditions (selection, classification, packaging and storage) and insufficient technology to improve the presentation of the product. This increases post-harvest losses - which range between 12 and $25 \%$, depending on the technological level of the production system - and affects the sector's competitiveness [2]. In order to reduce postharvest losses, it is necessary to understand the physiological factors associated to fruit deterioration, and to know the most adequate postharvest degreening technologies, so that senescence can be delayed in order to preserve quality as best as possible [24]. In addition, it is important to consider that fruit perishability can be associated to elevated water contents, respiratory rate and (despite the fact that mandarin is not a climacteric fruit) sensitivity to ethylene, among other factors. 
Recent research has been conducted on the impact of methyl jasmonate (MeJA) on the biosynthesis of volatile compounds in climacteric fruits such as apple and tomato, wherein ripening modulation through ethylene - independent routes constitutes a novel postharvest alternative [17]. Applications to non - climacteric fruits such as strawberry have rendered good results which favor the application of this compound as a postharvest degreening alternative $[7,8,9,16]$. In mandarin, this chemical agent has been used during postharvest to reduce the incidence of the green mold disease, which is caused by Penicillum digitatum [14]. MeJA is a signaling molecule that mediates diverse development processes and defense responses in face of biotic and abiotic stress. In addition, it improves resistance to both disease and citrus chilling injury during postharvest $[5,14,30,31]$. No degreening effect of MeJA on mandarin has been reported so far, due to the widespread use of ethylene for this purpose.

El Hadi et al. [10], Flores et al. [11] and Liu et al. [17] have demonstrated that ethylene plays a central role in promoting fruit ripening. However, the role of jasmonic acid (or of its ester, MeJA) in this process via accumulation of lycopene and $\beta$ carothene may constitute a feasible degreening alternative to the undesirable effects of ethylene during postharvest.

As an agronomic management practice, degreening is intended for the improvement of fruit color, mainly in tropical areas, where this feature is relatively weak $[3,25,28]$. The constantly elevated temperatures of these regions determine elevated chlorophyll levels in citrus fruit rind, which, consequently, retains its green color at the expense of the intense orange tone it reaches in subtropical countries [12]. Naturally, this leads to a loss of competitiveness in the sector.

Mayuoni et al. [20] state that ethylene degreening in orange, grapefruit and mandarin increases fruit chlorophyll degradation, respiration and ethylene production, but does not have any significant effect on total soluble solids, titratable acidity or volatile compound emission, thus not negatively affecting taste. The magnitude of this respiration increase is a function of ethylene concentration, but the treatment does not trigger the production of endogenous ethylene and, consequently, does not usually accelerate ripening in non-climacteric fruits $[15,27]$.

Based on these results, we hypothesized that MeJA improves postharvest fruit quality by performing independently from ethylene to promote pigment biosynthesis during the degreening of non climacteric fruits such as mandarin var. Arrayana.

\section{MATERIALS AND METHODS}

Research was conducted on mandarin (Citrus reticulata L.) var. Arrayana fruits at commercial ripeness, selected for size uniformity and absence of damage or infection. The chemical agents employed for the treatments were: reactive 1Methylcyclopropene $0.43 \%$ (1-MCP; Rohm and Haas); Ethrel® 480 SL (Bayer CropScience) (Ethephon ai: 2 - (chloroethyl) phosphonic acid, 480g $\mathrm{L}^{-1}$ ) and reactive methyl jasmonate 96\% (MeJA; Sigma Aldrich; $\delta 1.03 \mathrm{~g} \mathrm{~mL}^{-1}, 25^{\circ} \mathrm{C}$ ).

During postharvest, the studied fruits were evaluated for changes associated to $\mathrm{MeJA}$ at $18^{\circ} \mathrm{C}$ and $65 \%$ relative humidity $(\mathrm{RH})$. A completely randomized experimental design was used for the application of six treatments: MeJA $1 \mu \mathrm{M}, 24 \mathrm{~h}$; ethylene (ET) 1000 ppm, $20 \mathrm{~min} ; 1$ Methylcyclopropene (1-MCP) $0.5 \mu \mathrm{L} \mathrm{L}^{-1}, 2 \mathrm{~h}$; the following combinations: 1-MCP+MeJA and 1$\mathrm{MCP}+\mathrm{ET}$; and a control treatment. Each treatment contained four repetitions of the experimental unit (which was made up of five fruits), for a total of 24 experimental units. Postharvest parameters were monitored periodically for 18 days on 9 sampling dates. The parameters respiration rate (RR), weight loss (WL\%), color index (CI) and total chlorophyll (ChlTotal) were assessed every two days; whereas total soluble solids (TSS), firmness (Newtons - N), and total titratable acidity (TTA) were measured every seven days.

MeJA was applied in $2 \mathrm{~L}$ hermetic chambers at a concentration of $1 \mu \mathrm{L} \mathrm{L}^{-1}$ and a temperature of $20^{\circ} \mathrm{C}$ for $24 \mathrm{~h}$ (14), according to methodology by Liu et al. [17]. The application of 1-MCP $\left(0.5 \mu \mathrm{L} \mathrm{L}^{-1} 2 \mathrm{~h}\right)$ was carried out according to methodology by Gómez et al. [13]. Ethylene application $\left(1000 \mathrm{mg} \mathrm{L}^{-1}\right)$ was preceded by a 20-minute Ethrel treatment. Having received the treatments, the fruits were left at room temperature $\left(18^{\circ} \mathrm{C}\right)$ in thermoformed polyethylene terephthalate (plastic) boxes. In treatments 1-MCP + ethylene and 1-MCP + MeJA, both ethylene and MeJA were applied five days after pretreatment with 1-MCP. Storage and application conditions were the same in all treatments.

The statistical analysis included normality and variance homogeneity tests, followed by analysis of variance and a Tukey test $(\mathrm{P} \leq 0,05)$, all conducted in SPSS statistics 20 and SAS 9.2.

\section{RESULTS AND DISCUSSION}

In the studied mandarin fruits subjected to treatments with ethylene, 1-MCP or MeJA, neither RR nor TSS showed significant changes. This is, indeed, typical of non-climacteric fruits, wherein although respiratory changes correlate directly with ethylene concentration, the treatment does not increase endogenous ethylene production. As a consequence, ethylene bears no significant ripening 
effect, while it does bring along undesirable physiological disorders [15, 27].

In mandarin, not all processes associated to ripening are ethylene - dependent, which might also be the case in other species $[4,10,17]$. In the current study, the RR showed a steady trend during the 18 DATI. This implies that there are no significant respiratory intensity or ethylene production changes after physiological maturity [15, 24]. The current results stand within the RR range reported by Pássaro et al. [24] for citrus fruits (5 to $15 \mathrm{mg} \mathrm{CO} 2 \mathrm{~kg}^{-1} \mathrm{~h}^{-1}$ ).

a.

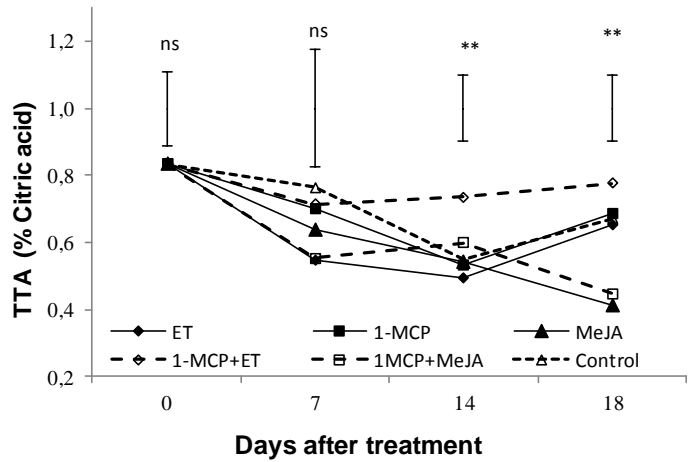

C.

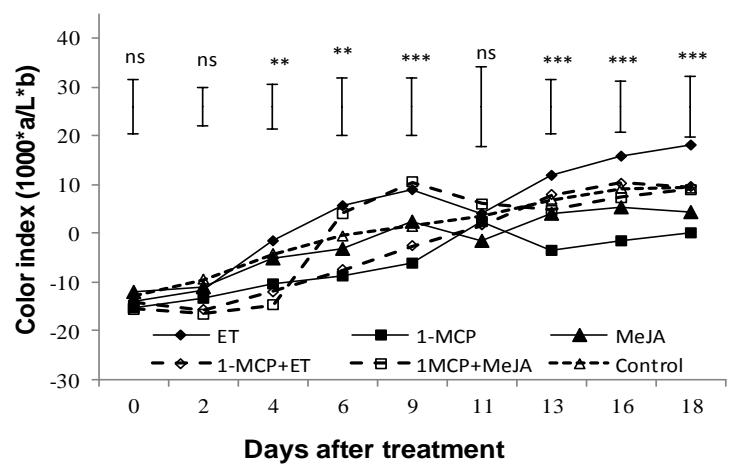

The treatments produced significant effects on TTA $(\mathrm{P} \leq 0.05)$ in the last two samplings, i.e., at 14 and 18 DATI (Figure 3a). Since 14 DATI, the treatments MeJA and 1-MCP + MeJA produced a decrement in this parameter, to the point of determining significant differences with respect to $\mathrm{MCP}+\mathrm{ET}$ at 18 DATI. This might be due to fruit dehydration associated to membrane integrity losses, in turn resulting from ethylene application.

b.

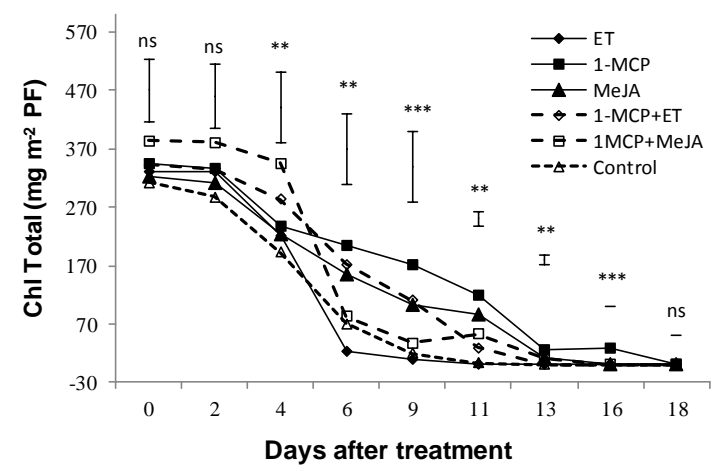

Treatments: MeJA, $1 \mu \mathrm{M}$ for $24 \mathrm{~h}$; ET, $1000 \mathrm{mg} \mathrm{L}-$ 1, $20 \mathrm{~min} ; 1-\mathrm{MCP}, 0.5 \mu \mathrm{L} \mathrm{L}-1,2 \mathrm{~h}$; and the combinations: $1-\mathrm{MCP}+\mathrm{MeJA}$ and 1-MCP+ET. ET and MeJA applications were carried out five days after that of 1-MCP.

Figure 3. Effects of treatments with methyl jasmonate (MeJA), ethylene (ET) and 1-Methylcyclopropene (1MCP); and their combinations: 1-MCP + ET and 1-MCP + MeJA, all applied on mandarin var. Arrayana fruits at $18^{\circ} \mathrm{C}$ and $65 \%$ RH. a) Total titratable acidity (TTA), b) Total chlorophyll (Chl Total), and c) Color Index.

(*) $5 \%$ statistical significance; (**) $1 \%$ statistical significance; (***) $0.1 \%$ statistical significance; (ns) no significant differences according to ANOVA. The vertical bar represents the least significant difference (LSD) of the Tukey test. The difference between two average data at any sampling date is considered to be significant when it is larger than the corresponding LSD value $(\mathrm{P} \leq 0.05)$.

As to ChlTotal, no significant differences were observed in the first two samplings, but on the fourth day, the highest (and significant) score for this parameter was reached under treatment 1-MCP + MeJA (Figure 3b). Under either MeJA or 1-MCP treatments, the chlorophyll degradation rate resulted in not so steep, but still decreasing slopes when compared to those obtained under the ethylene treatment. Hence, degreening via carotenoid biosynthesis could probably be handled more adequately in fruits treated with MeJA. As expected, 1-MCP bore a significant effect on ChlTotal, starting from the sixth day and until the end of the experiment. The reduction of this parameter in response to the application of MeJA shows an intermediate trend between the results obtained with the ethylene and 1-MCP treatments, significant differences being observed since the fourth day (Figure 3b).

In this way, MeJA comes to be a suitable fruit conservation product, since it is efficient in 
reducing chlorophyll degradation rate and, probably, carotenoid biosynthesis. Chlorophyll content reduction is due to an increase in chlorophyllase activity, which is, in turn, promoted by ethylene and inhibited by 1-MCP [21, 29]. However, the effect of MeJA on these proteins with enzymatic activity has not yet been reported in citrus fruits.

The color index resulting from the 1-MCP treatment remained among the lowest values until 4 DATI, when it became significantly smaller than the one determined by the ethylene treatment. After the application of MeJA at 5 DATI (thus completing the 1-MCP + MeJA treatment), the CI rose and then assumed a similar behavior to that obtained under the ethylene treatment until the end of the experiment (Figure 3c). At 14, 16 and 18 DATI, the evaluated fruits exhibited the color appearance illustrated in figure 3.1. Hence, time (as measured in days) is certainly important for the case, as it is necessary to start from a CI value of -17 to reach a commercial color that is likely to be appreciated by the consumer. Although the most widespread practice for degreening is the use of ethylene, MeJA could be applied to obtain slower degreening rates in exported fruits. Commercial CI levels could be obtained by starting from an initial value of -6 and proceeding to degreening without ethylene [1].

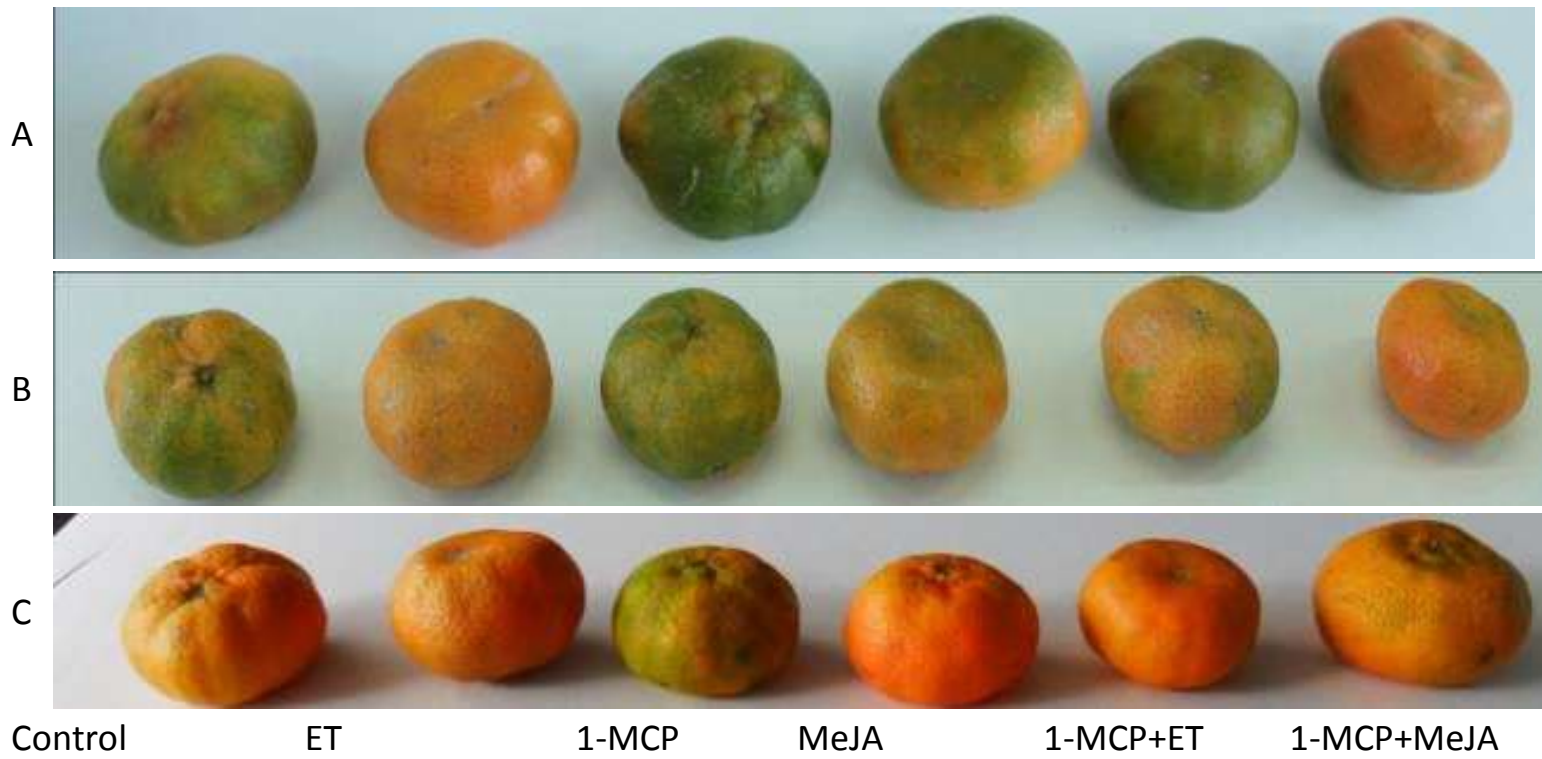

Figure 3.1. Effects of the treatments methyl jasmonate (MeJA), ethylene (ET) and 1-Methylcyclopropene (1-MCP); and of their combinations: 1-MCP + ET and 1-MCP + MeJA, all applied on mandarin var. Arrayana fruits, at $18^{\circ} \mathrm{C}$ and $65 \%$ RH. A) 14 , B) 16 , and C) 18 DATI.

In analyzing carotenoid biosynthesis during postharvest conservation of citrus fruits, Carmona [6] suggests the existence of alternative routes for transcriptional control which are not necessarily induced by ethylene. Contrastingly, the results of the current study indicate that the $1-\mathrm{MCP}$ treatment remarkably inhibited color development and chlorophyll degradation until 4 DATI, in close agreement with a previous report of approximately 5 days for this same inhibitor [13]. The current assessment of chlorophyll content and color index suggests that the use of MeJA favors the expression of genes involved in carotenoid biosynthesis and other processes, in an analogous way to that of exogenous ethylene.

The application of 1-MCP reduces color index increment and chlorophyll degradation, as also reported by Rodrigo et al. [26]. These effects on ripening are temporary because the application of the inhibitor does not necessarily block all ethylene receptors, which, at the cell membrane level, can be newly generated. When applying ethylene or MeJA, the processes involved in fruit coloring are reestablished five days after the application of 1MCP.

Color index increments are due to chlorophyll degradation and carotenoid exposition, mainly $\beta$-carotene and $\beta$-cryptoxanthin [32]. The processes associated to mandarin fruit ripening are not necessarily ethylene - dependent, alternative MeJA-induced-routes being possibly favored, as it also happens in climacteric fruits such as tomato [17] and apple [23].

In the current research, treatment 1-MCP + MeJA allowed a uniform coloring without browning damage in the studied mandarin var. Arrayana fruits. Besides inducing disease resistance in citrus crops, MeJA plays an important role in mandarin postharvest [22]. The current study found that its application favors desirable organoleptic features during postharvest. Therefore, and although it has not been previously reported, this compound might be a good mandarin degreening alternative. 
Regarding weight loss, Figure 3.2-a, illustrates how after 11 and 16 DATI the fruits treated with $1-\mathrm{MCP}+\mathrm{MeJA}$ lost significantly more weight than those treated only with MeJA. Weight loss was observed to increase during storage, the fruits treated with MeJA exhibiting a similar tendency to those under the other treatments.

a.

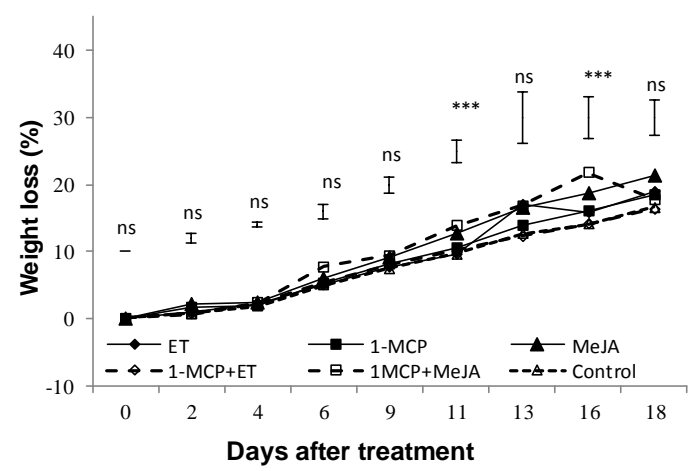

C.

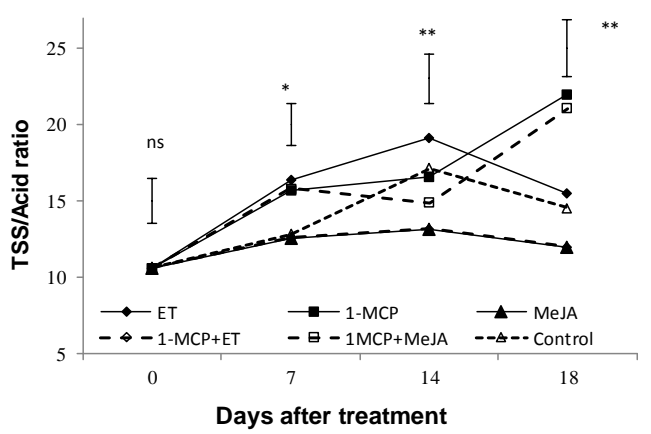

Provided that its application induces degreening, MeJA seems to be involved in processes associated to mandarin fruit ripening. Figure 3.2-a also illustrates how weight loss in the fruits treated with MeJA follows a similar trend to that of the fruits treated with ethylene.

b.

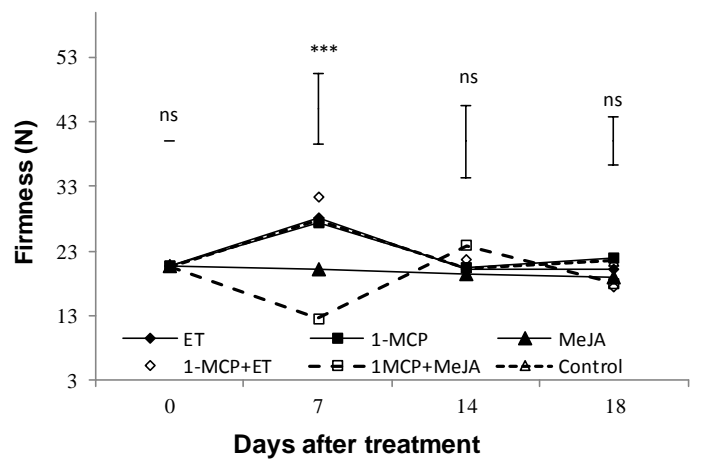

Treatments: MeJA $1 \mu \mathrm{M}$, for $24 \mathrm{~h}$; ET $1000 \mathrm{mg} \mathrm{L}^{-1}$, $20 \mathrm{~min} ; 1-\mathrm{MCP} \quad 0.5 \mu \mathrm{L} \quad \mathrm{L}^{-1}, 2 \mathrm{~h}$; and the combinations: 1-MCP + MeJA, and 1-MCP + ET. The application of ET and MeJA took place $5 \mathrm{~d}$ after treatment with 1-MCP.

Figure 3.2. Effects of the treatments methyl jasmonate (MeJA), ethylene (ET) and 1-Methylcyclopropene (1$\mathrm{MCP}$ ); and of the combinations 1-MCP + ET and 1-MCP + MeJA; all applied on Arrayana mandarin fruits at $18^{\circ} \mathrm{C}$ and $65 \%$ RH. a) Weight loss (WL\%). b) Firmness (N). c) TSS/acid ratio.

(*) $5 \%$ statistical significance; (**) $1 \%$ statistical significance; (***) $0.1 \%$ statistical significance; (ns) no significant differences according to ANOVA. The vertical bar represents the least significant difference (LSD) of the Tukey test. The difference between two average data at any sampling date is considered to be significant when it is larger than the corresponding LSD value $(\mathrm{P} \leq 0.05)$.

At 7 DATI, the ethylene, 1-MCP + ET, 1$\mathrm{MCP}$ and control treatments determined significant firmness increments when compared to 1-MCP + MeJA. Treatment MeJA determined a steady, intermediate trend in this parameter until the end of the experiment (Figure 3.2-b). However, ethylene application produces dehydration and epidermis hardening, which is unclear and calls for further research.

The stable and intermediate behavior of firmness (Figure 3.2-b) in the fruits treated with MeJA suggests that ripening might be more favored via biosynthesis of methyl jasmonate than through ethylene - associated induction.

At 7 and 14 DATI, the treatments MeJA and 1-MCP + ET determined significantly smaller TSS/acid ratio scores than those resulting from ethylene application. Since 14 DATI under the 1$\mathrm{MCP}+\mathrm{MeJA}$ and 1-MCP, this parameter increased significantly when compared to its behavior under ethylene application.

Due to an increase in TTA responding to ethylene application, the TSS/acid ratio decreased since 14 DATI (Figure 3.2-c). TSS/acid ratio during storage, in response to variations in TSS as substrate on the part of the fruit. However, starting 14 DATI, this ratio was found to decrease in the ethylene and control treatments, due to increments in TTA. The current results coincide with the literature recommendations on optimal TSS/acid ratio numbers, according to which this parameter should be above 7.5 [19]. In the current experiment, under treatment with MeJA this parameter is scored an average 9. The TSS/acid ratio constitutes an 
interesting post-harvest indicator of pandering mandarin degreening quality, which is actually assessed through the total soluble solid/total titratable acidity ratio. The tendency exhibited by the TSS/acid ratio under the treatments applied in the present research shows the advantages of using MeJA as citrus postharvest technology applied to arrayana mandarin in the present case.

In studies conducted on climacteric and non-climacteric fruits, ripening has been found to be regulated through at least two biochemical routes associated to contrasting gene expressions. An ethylene - dependent route is linked to the expression of genes implied not only in the biosynthesis of lycopene, carotenoids and components of aroma, but also in the metabolism and expression of the enzyme ACC synthase. A second, ethylene - independent route is associated to genes that codify for the enzymes ACC oxidase and the chlorophyllases [17]. Hence, not all the processes associated to fruit ripening are ethylene dependent.

The current results allow stating that MeJA affects the evaluated post-harvest parameters, namely weight loss, color index, total chlorophyll, firmness, total soluble solids and total titratable acidity. The response to the application of 1-MCP five days before treatment with MeJA is certainly good, to the point that it can be compared to that obtained by applying ethylene under the same conditions. This suggests that MeJA is, like ethylene, involved in chlorophyll degradation and carotenoid accumulation in non-climacteric fruits like mandarin. The fruits evaluated in the current study were kept in storage during postharvest and assessed in terms of commercial and degreening ripeness. For such purpose, parameters such as firmness, color change and soluble solids content, among others, were taken into consideration. Hence, future studies can be fruitfully oriented to assessing the behavior of organic acid and phenolic compound contents, as well as the production of volatiles, all of which depend, to a large extent, on the application of degreening products during postharvest.

\section{CONCLUSION}

A Pretreatment with 1-Methylcyclopropene partially reduced the coloring stimulation that takes place during postharvest storage and conservation of mandarin fruits. On these grounds, the subsequent application of methyl jasmonate for degreening induced progressive pigmentation, finally rendering a uniform color without damage. In non-climacteric fruits, methyl jasmonate might be involved in chlorophyll degradation and carotenoid biosynthesis. The current results demonstrate the potential of this compound as a postharvest alternative for Arrayana mandarin at $18^{\circ} \mathrm{C}$.

\section{RECOMMENDATIONS}

Regarding future research perspectives, it is important to conduct experiments in which methyl jasmonate is applied to fruits subjected to low temperatures, in order to determine its effect on the reduction of chilling injury. Just as well, it is necessary to evaluate its effect on the production of volatiles, with the aim of establishing its influence on fruit organoleptic characteristics.

\section{ACKNOWLEDGEMENTS}

We want to give special thanks to the postharvest laboratory of the school of agrarian sciences and researchers at Agronomy of Universidad Nacional de Colombia, Bogota campus; and to the Colombian Ministry of Agriculture and Rural Development, for financial support of the project "Evaluation of different postharvest technologies for mandarin (Citrus reticulata) fruit conservation", labeled CE- 13158-111-09, which framed the conduction of the present research work. Finally, we also thank CENIRED for valuable support in the execution of the project.

\section{REFERENCES}

[1] Abad, I.; Jávega, J.M.M.; Cuquerella, J. 2003. Respuesta al tratamiento de cuarentena por frío de la mandarina mioro sometida a desverdización. Revista Iberoamericana de Tecnología Postcosecha. 5(2): 117-121.

[2] Aguilar, P.M.; Escobar, J.; Pássaro, C.P. 2012. Cítricos: cultivo, poscosecha e industrialización, pp. 367. In: L. Garcés y C.P. Pássaro (eds.). Situación actual de la cadena de cítricos en Colombia: limitantes y perspectivas. Corporación Universitaria Lasallista. Itagüí, Colombia,

[3] Barry, G.; Wyk, A. 2006. Low-temperature cold shock may induce rind colour development of 'Nules Clementine' mandarin (Citrus Reticulata Blanco) fruit. Postharvest Biology and Technology. 40: 82-88.

[4] Blanch, G.P.; Flores, G.; Castillo, M.L.R. 2011. Influence of methyl jasmonate in conjunction with ethanol on the formation of volatile compounds in berries belonging to the Rosaceae. Postharvest Biology and Technology. 62: 168-78.

[5] Cao, S.; Zheng, Y.; Yang, Z.; Tang, S.; Jin, P.; Wang, K.; Wang, X. 2008. Effect of methyl jasmonate on the inhibition of Colletotrichum acutatum infection in loquat fruit and the possible mechanisms. Postharvest Biology and Technology. 49(2): 301-307. 
[6] Carmona, M.L. 2010. Biosíntesis de carotenoides durante la conservación postcosecha de frutos cítricos. Doctoral dissertation. Universidad Politécnica de Valencia, Spain. 150 p.

[7] De la Peña Moreno, F., Blanch, G.P., Ruiz del Castillo, M.L. 2010a. Effect of (-) - and (+) - methyl jasmonate on the formation of aroma-active esters in strawberry fruit. Eur. Food Res. Technol. 231: 829-834.

[8] De la Peña Moreno, F.; Monagas, M.; Blanch, G.P.; Bartolomé, B.; Ruiz del Castillo M.L. 2010b. Enhancement of phenolic and aroma compounds in strawberry fruit through methyl jasmonate vapour treatment. Eur. Food Res. Technol. 230: 989-999.

[9] De la Peña Moreno, F.; Blanch, G.P.; Flores, G.; Ruiz del Castillo, M.L. 2010c. Impact of postharvest methyl jasmonate treatment on the volatile composition and flavonol content of strawberries. J. Sci. Food Agric. 90: 989-994.

[10] El Hadi, M.A.; Zhang, F.J.; Wu, E.F.; Zhou, C.H.; Tao, J. 2013. Advances in fruit aroma volatile research. Molecules. 18: 8200-8229.

[11] Flores, G.; Blanch, G.P.; Ruiz del Castillo, M.L. 2013. Isolation of the four methyl jasmonate stereoisomers and their effects on selected chiral volatile compounds in red raspberries. Food Chemistry. 141(3): 29822987.

[12] Goldschmidt, E.E. 1997. Carbohydrate supply as a limiting factor for citrus fruit growth and productivity. HortScience. 32(3): 550-551.

[13] Gómez, C.A.; Balaguera-López, H.E.; García, J.C.; Herrera, A.O.; Flórez, V.J. 2014. Efecto de 1-Metilciclopropeno en la poscosecha de mandarina (Citrus Reticulata L.) var. Arrayana. Rev. Fac. Nal. Agr. Medellín. 67(2): 1159-1162.

[14] Guo, J.; Fang, W.; Lu, H.; Zhu, R.; Lu, L.; Zheng, X.; Yu, T. 2014. Inhibition of green mold disease in mandarins by preventive applications of methyl jasmonate and antagonistic yeast Cryptococcus laurentii. Postharvest Biology and Technology, 88(0): 72-78.

[15] Kader, A.A. 2002. Postharvest Technology of Horticultural Crops. 3rd ed., Division of Agriculture and Natural Resources. UCANR Publications. University of California (System). Vol. 3311.

[16] Kondo, S., Mattheis, J. 2006. Aroma volatile biosynthesis in apples at harvest or after harvest affected by jasmonates. ActaHortic. 712: 381-388.

[17] Liu, L.; Wei, J.; Zhang, M.; Zhang, L.; Li, C.; Wang, Q. 2012. Ethylene independent induction of lycopene biosynthesis in tomato fruits by jasmonates. Journal of Experimental Botany. 63(16): 5751-5761.

[18] MADR, Ministerio de Agricultura y Desarrollo Rural de Colombia. 2015. Estadísticas Anuales. (2013). In: Anuario estadístico del sector agropecuario 2012. November 28 of 2013. Bogotá Colombia. Consulted on March 31, 2015. http://www.agronet.gov.co/www/htm3b/Re portesAjax/VerReporte.aspx

[19] Martínez-Jávega, J.M.; Cuquerella, J.; Del RÍO, M.A.; Navarro, P. 2001. Aplicación de la tecnología postcosecha en la exportación de mandarinas con restricciones cuarentenarias. Rev. Levante Agrícola. 355: 107-112.

[20] Mayuoni, L.; Tietel, Z.; Patil, B.S.; Porat, R. 2011. Does ethylene degreening affect internal quality of citrus fruit? Postharvest Biology and Technology. 62(1): 50-58.

[21] Mccollum, G.; Maul, P. 2007. 1Methylcyclopropene Inhibits degreening but stimulates respiration and ethylene biosynthesis in grapefruit. Hortscience. 42(1): 120-24.

[22] Meng, X.; Han, J.; Wang, Q.; Tian, S. 2009. Changes in physiology and quality of peach fruits treated by methyl jasmonate under low temperature stress. Food Chemistry. 114(3): 1028-1035.

[23] Öztürk, B.; Altuntas, E.; Yildiz, K.; Ozkan, Y.; Saracoglu, O. 2013. Effect of methyl jasmonate treatments on the bioactive compounds and physicochemical quality of 'Fuji' apples. Ciencia e Investigación Agraria. 40(1): 201-211.

[24] Pássaro, C.P.; Navarro, P.; Salvador, A. 2012. Poscosecha. pp. 367. In: L. Garcés y C.P. Pássaro (eds.). Cítricos: cultivo, poscosecha e industrialización. Corporación Universitaria Lasallista. Itagüí, Colombia.

[25] Porat, R. 2008. Degreening of citrus fruit tree forest. Sci. Biotechnol. 2: 71-76.

[26] Rodrigo, M.J.; Alquézar, B.; Alós, E.; Lado, J.; Zacarías, L. 2013. Biochemical bases and molecular regulation of pigmentation in the peel of citrus fruit. Scientia Horticulturae. 163: 46-62.

[27] Taiz, L.; Zeiger, E. 2006. Auxin: The growth hormone. Plant Physiology. 4: 467487. 
[28] Wardowsky, W.M.; Miller, W.F.; Grierson, D. 2006. Degreening. Fresh citrus fruits. Longboat Key: Florida Science Source. 277-298 p.

[29] Win, T.; Srilaong, V.; Heyes, J.; Kyu, K.; Kalanayarat, S. 2006. Effects of different concentrations of 1-MCP on the yellowing of west indian lime (Citrus Aurantifolia, Swingle) Fruit. Postharvest Biology and Technology. 42: 23-30.

[30] Yan, Y.; Borrego, E.; Kolomiets, M.V. 2013 Jasmonate biosynthesis, perception and function in plant development and stress response. Lipid Metabolism. 393-442 p.

[31] Yu, Y. 2013. Imaging of jasmonic acid binding sites in tissue. Analytical biochemistry. 440(2): 205-211.

[32] Zhou, J.Y.; Sun, C.D.; Zhang, L.L.; Dai, X.; Xu, C.J.; Chen, K.S. 2010. Preferential accumulation of orange-colored carotenoids in ponkan (Citrus reticulata) fruit peel following postharvest application of ethylene or ethephon. Scientia Horticulturae. 126(2): 229-35.

APA MLA Chicago Carlos Alberto Gómez. "Methyl Jasmonate, a Degreening Alternative for Mandarin (Citrus Reticulata L.) Var. Arrayana Fruits ." International Journal of Engineering Research and Applications (IJERA) 7.7 (2017): 22-29. 